\title{
The Phenology of Wilderness Use: Backcountry Recreation in a Changing Climate $^{\mathscr{A}}$
}

\author{
ADRIENNE MARSHALL \\ Department of Water Resources, University of Idaho, Moscow, Idaho \\ VAN BUTSIC \\ Department of Environmental Science, Policy, and Management, University of California, Berkeley, Berkeley, California \\ JOHN HARTE \\ Energy and Resources Group, and Department of Environmental Science, Policy, and Management, \\ University of California, Berkeley, Berkeley, California
}

(Manuscript received 16 August 2017, in final form 17 November 2017)

\begin{abstract}
Phenology studies are a critical tool for identifying the ways that changing climate affects species and ecosystems. Here, a phenological framework was used to assess the sensitivity of human behavior to temperature and hydroclimate variables that are likely to change as temperatures warm under twenty-firstcentury climate change. The timing of visitation to wilderness areas of the Sierra Nevada was used as a case study. Visitation timing was assessed using a backcountry permit database and data collected from weblogs or blogs. Mean, earliest, and latest visitation dates were regressed against temperature, streamflow, and snowpack variables: seasonally averaged air temperatures, snow water equivalent (SWE) in spring months, center of timing (CT), and total annual flow. Mean visitation was sensitive to CT, total annual flow, April and May SWE, and spring and summer temperatures, with visitors advancing $0.20-0.28$ days for each day advance in CT and 3.7 to 5.7 days for each degree Celsius increase in summer temperatures. Visitors appear to be partially sensitive to both hydroclimate and temperature, suggesting that visitation may occur earlier as spring snow decreases, but also that because of this partial sensitivity, visitors may interact with ecosystems in a different phenological stage as the climate warms. Managers of these areas should plan for changing timing of visitation and should also consider ways that visitors interacting with different hydroclimatic and ecosystem conditions may influence management strategies.
\end{abstract}

\section{Introduction}

Phenology studies that assess changing seasonal timing of organisms are a critical tool for observing and projecting the impacts of climate change on species and ecosystems. One important point that has emerged from the phenology literature is that changing interactions between species may be more important than seasonal changes in individual species (Parmesan 2006). Humans are one species that may change their behavior under a

Supplemental information related to this paper is available at the Journals Online website: https://doi.org/10.1175/WCAS-D-170087.s1.

Corresponding author: Adrienne Marshall, adriennemarshall@ uidaho.edu changing climate and that play an important role in protected areas that receive millions of human visitors each year. This volume positions humans as active participants in these ecosystems, making it prudent to consider how humans and protected area ecosystems influence each other (Machlis 1989).

Human activities in protected areas impact soil, vegetation, wildlife, and water (Leung and Marion 1999) through overgrazing, compaction of soils, threat of wildfire and overgathering of fuel, and collection and harassment of wildlife (van Wagtendonk and Parsons 1996). A recent review of recreation impacts on wildlife suggested that nonmotorized recreation has a larger effect than does motorized recreation (Larson et al. 2016). Moreover, winter activities are more impactful than those in other seasons, perhaps due to food availability and the energetic costs to animals of traveling over snow to flee 
human presence, suggesting that the timing of visitation is important (Larson et al. 2016). In many protected areas, land managers have recognized the potential impacts of human visitation and have established quota systems to regulate the timing and magnitude of backcountry visitation. In the United States, this practice originated in Sequoia and Kings Canyon National Parks (SEKI), which are the geographic focus of this study (van Wagtendonk and Parsons 1996).

Across multiple spatial scales and regions, visitation to protected areas is sensitive to climate (Table 1). Regression analyses of monthly temperatures and visitation across all national parks of the United States suggest that warming will likely increase visitation and extend the season of visitation at most parks (Fisichelli et al. 2015). In the Canadian Rockies, visitor surveys and regression analyses relating climate to visitation projected a $10 \%-36 \%$ increase in visitation by the 2050s, though the more extreme projected biophysical changes in the late twentyfirst century resulted in a decrease in visitor-stated interest in visitation (Scott et al. 2007). Similar methods in the Colorado Rockies have suggested a $10 \%-14 \%$ increase in visitation, though only a relatively small proportion of survey respondents indicated that they would change their behavior in response to climate change scenarios (Richardson and Loomis 2004). In one park in southern Canada, weather visitation models suggested that annual park visitation might increase by $3.1 \%$ annually per additional degree $\left({ }^{\circ} \mathrm{C}\right)$ of warming, with threshold effects at the warmest and coolest temperatures (Hewer et al. 2016). Similarly, regression analyses suggest that visitation to Ontario's provincial parks may increase by $15 \%-56 \%$ by the 2050s because of the relationships between visitation and climate and that this effect may be compounded by demographic changes (Jones and Scott 2006a).

The timing of tourism, as well as magnitude, may be affected by weather and climate. Across North America, warming may redistribute climatic conditions for tourism in ways that vary seasonally, with northern cities gaining longer tourism seasons (Scott et al. 2004). Visitation in U.S. national parks has already shifted 4 days earlier since 1979, and of nine parks with an increase in mean spring temperature, seven of those also experienced an advance in visitor timing (Buckley and Foushee 2012). In Alaska, projections suggest that peak visitation in three national parks could expand into the historic shoulder season, though these changes could be mediated by the effects of climate change on park attractions (Albano et al. 2013). Moreover, studies in southern Ontario suggest that warming temperatures may result in spring and fall increases in visitation but that summer visitation may plateau or decline (Hewer et al. 2016).
While studies show that temperature affects the magnitude and timing of visitation to protected areas, other climatic variables, such as heavy rain and strong winds, also affect visitation and may even have stronger effects than temperature (Hewer et al. 2015). Overnight wilderness users in mountainous regions are a group that may be sensitive to these climatic variables and to the indirect effects of warming temperatures. These users have been relatively unstudied in existing assessments of climate change and tourism, yet are an important group because of the multiday nature of their trips and presence in otherwise undisturbed areas. Hydroclimatic variables, particularly the magnitude and timing of streamflow and snowpack, may exert control over the timing of overnight wilderness use because of the potential for high streamflow and deep snowpack to impede travel.

Snowpack and streamflow are temperature sensitive and are projected to change with anthropogenic climate change, with observations and projections of earlier streamflow timing, reduced snowpack, and spatially variable changes in overall discharge (e.g., Hayhoe et al. 2004; Stewart et al. 2004; Ficklin et al. 2012). Global temperatures are projected to rise by $1.1^{\circ}-2.6^{\circ} \mathrm{C}$ under the moderate emissions scenario represented by representative concentration pathway (RCP) 4.5 or by $2.6^{\circ}-4.8^{\circ} \mathrm{C}$ under the more extreme RCP8.5 (IPCC 2013). Warming in the Sierra Nevada range of California is projected to have serious hydrologic consequences. The ratio of precipitation falling as snow is projected to decrease (Barnett et al. 2008), which will reduce the area of the Sierra Nevada that can be characterized as strongly snow dominated by $14 \%$ by the late twenty-first century (Klos et al. 2014). The 1 April snow water equivalent (SWE) has already decreased across the western United States, with the exception of the southern Sierra Nevada (Mote 2006). Despite the resilience of the southern Sierra Nevada SWE magnitude to twentieth-century warming, 1 April SWE in the Kings River is projected to decrease by $24 \%-43 \%$ by $2050-80$ (Maurer 2007), while 1 April SWE in the southern Sierra is projected to decrease by $22 \%-93 \%$, depending on the emissions scenario and time period (Vicuna et al. 2007). Streamflow timing is projected to advance by 1-6 weeks in the twenty-first century, depending on warming scenario and time period (Maurer 2007; Young et al. 2009; He et al. 2013). While reduced SWE and earlier streamflow timing are relatively certain, projected changes in streamflow volume are uncertain, ranging from positive to negative throughout the Sierra Nevada (Ficklin et al. 2012; He et al. 2013). These changes in hydroclimate may affect the behavior of overnight wilderness users. 


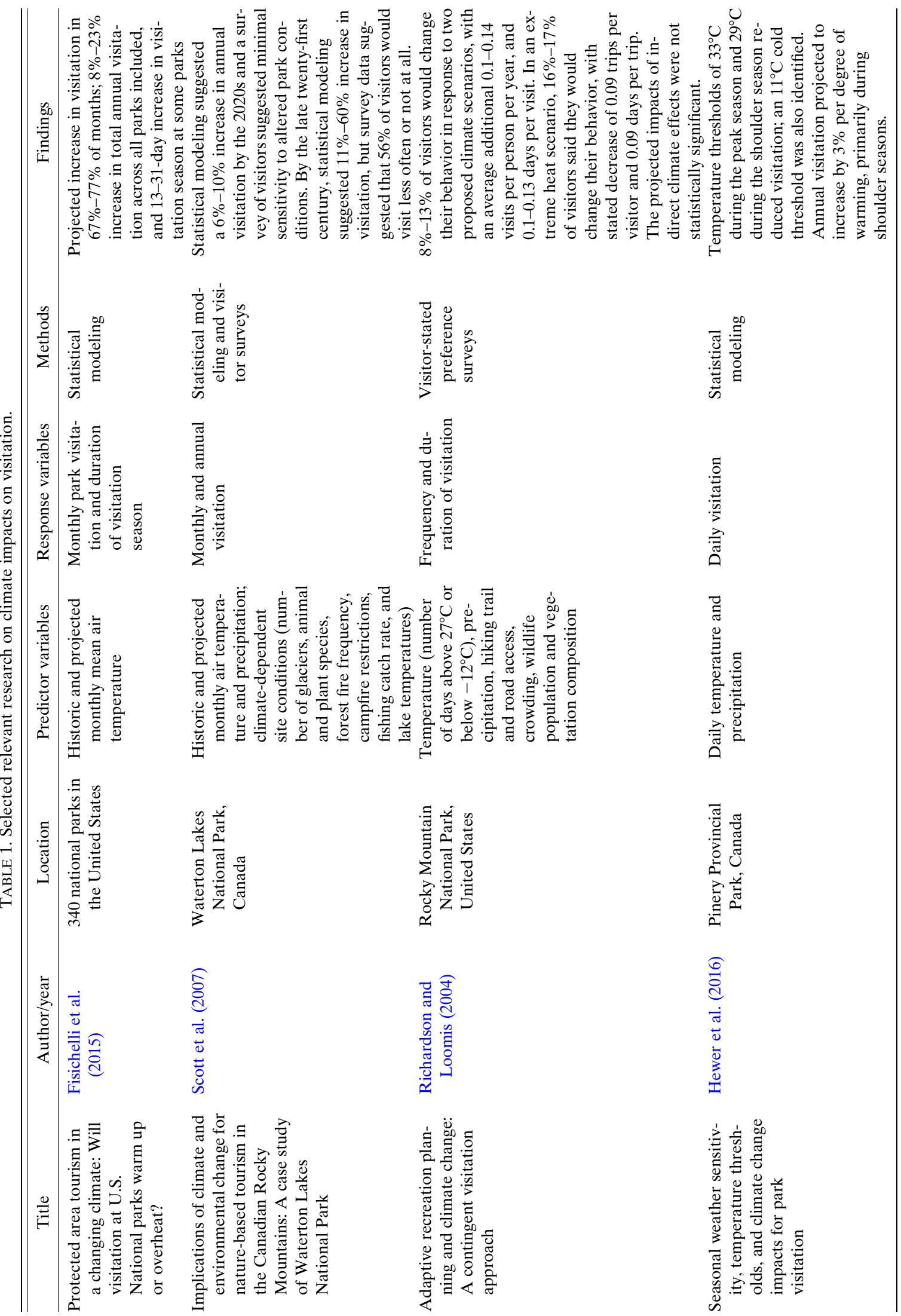




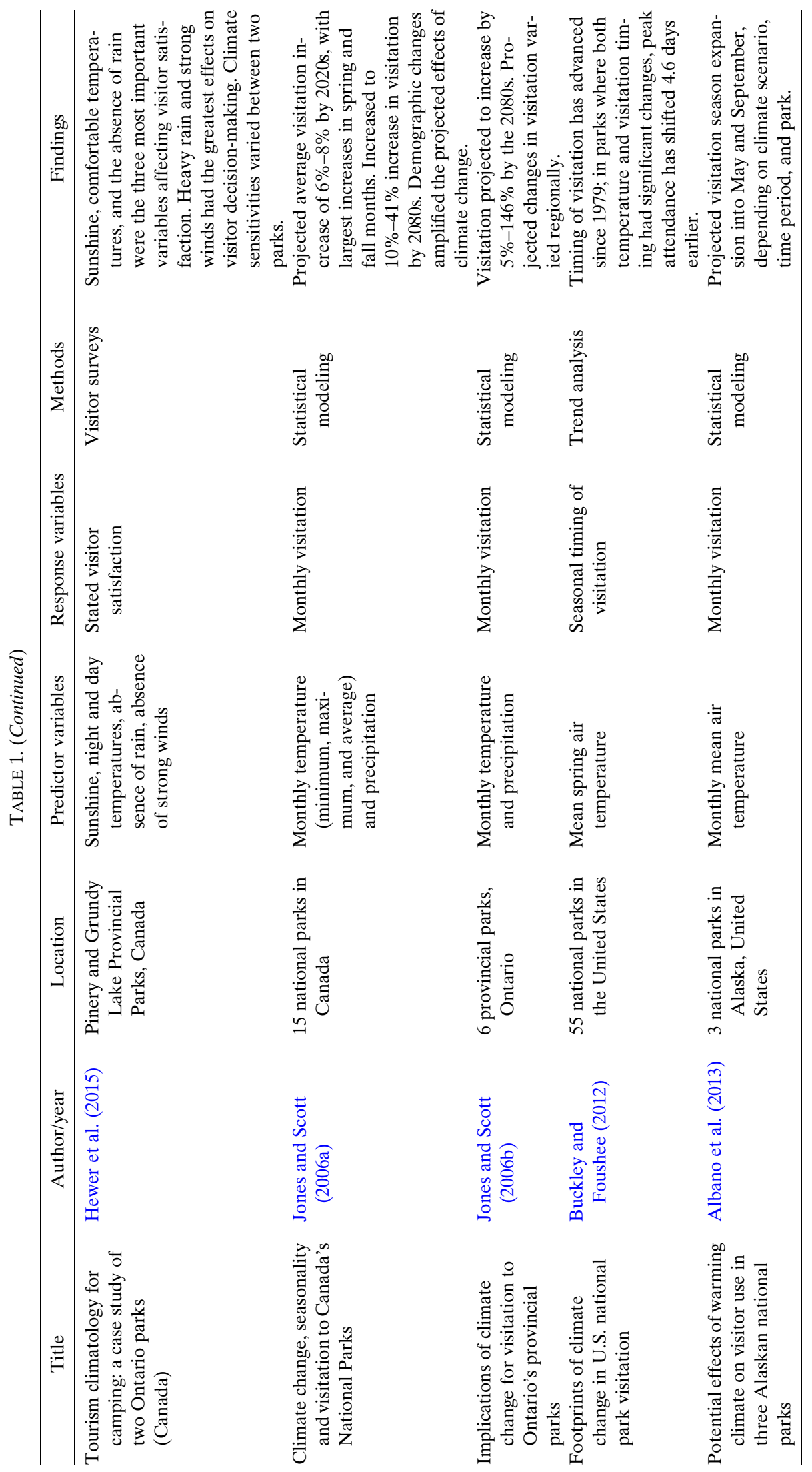




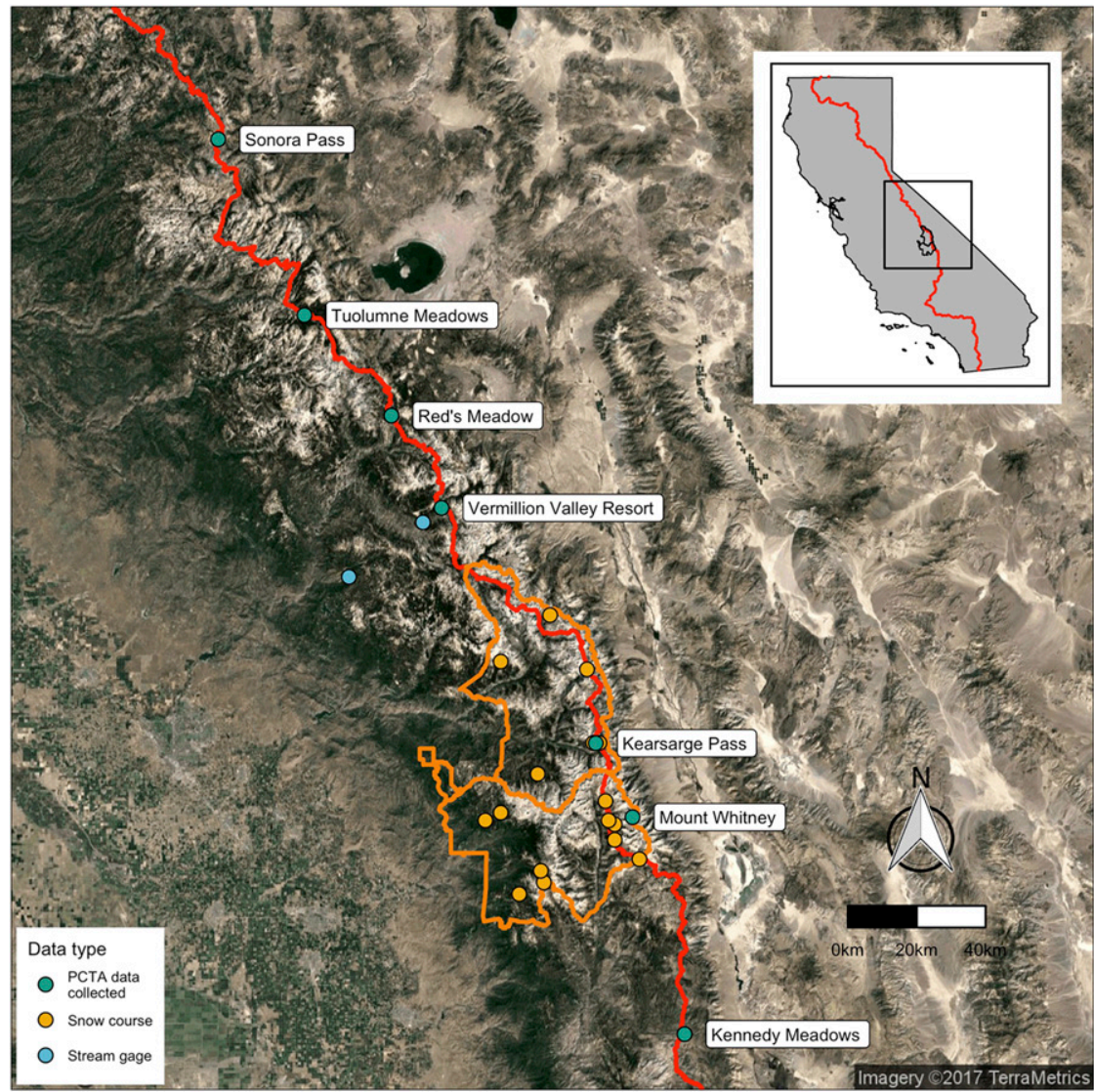

FIG. 1. Study area marked with locations for hydroclimate and PCTA permit holder data, with the PCT in red and SEKI in orange. Stream gauges are outside SEKI but in watersheds draining SEKI. Built with ggmap (Kahle and Wickham 2013).

The goal of this study is to establish the sensitivities of visitation timing for two distinct visitor groups to interannual variability in hydroclimate variables and temperature in order to understand how visitation timing may respond to climate change. We identified and studied two different groups of overnight wilderness visitors: the first are those who obtain their backcountry permits through the National Park Service (NPS) and are referred to throughout this study as "NPS permit holders." NPS permit holders form the vast majority of visitors to SEKI wilderness. In addition, there is a smaller but rapidly growing group of users that travel long distances $(>805 \mathrm{~km})$ on the Pacific Crest Trail (PCT). These users obtain their permits from the Pacific Crest Trail Association (PCTA) and are referred to in this study as "PCTA permit holders."

Understanding the timing of backcountry visitors, and how that timing is affected by changing climate variables, will allow managers to plan for visitation and adjust quota timing if necessary. Furthermore, it provides a basis for further inquiry of how changing human phenology may interact with the changing phenology of other species. Changing phenology of wilderness use may be relevant to wilderness visitors, managers of protected areas, and local businesses that rely on tourism and to ecosystems that may be stressed by climate change and are impacted by visitor use.

\section{Methods}

\section{a. Study area}

The geographic focus of this study is the designated wilderness of SEKI (Fig. 1). Located in the southern Sierra Nevada range of California, SEKI spans an elevation range from 418 to $4418 \mathrm{~m}$ above mean sea level. These national parks cover $3504 \mathrm{~km}^{2}, 97 \%$ of which is managed as wilderness (NPS 2015). This area includes glacially carved canyons, lake basins, wet meadows, and montane, subalpine, and alpine forests (NPS 2015). Characteristic animal species in the area include black bear (Ursus americanus), mule deer (Odocoileus hemionus), acorn woodpeckers (Melanerpes formicivorus), American 


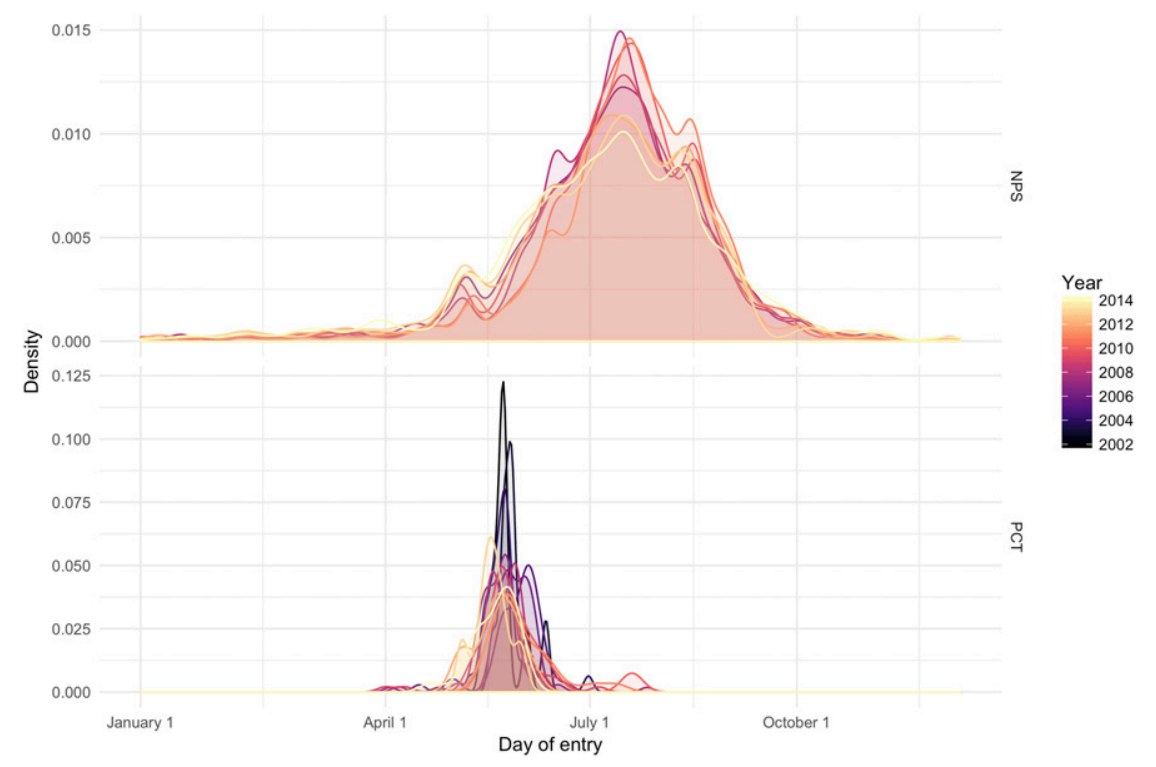

FIG. 2. Distribution of visitation dates for NPS and PCTA permit holders in each year. Visitation was smoothed with a Gaussian kernel.

pika (Ochotona princeps), and Sierra Nevada bighorn sheep (Ovis canadensis sierrae; NPS 2015). Four major rivers drain the parks, flowing into the Sacramento-San Joaquin delta and providing freshwater resources to the rest of the state (NPS 2015). Over the period from 1979 to 2016, the NPS issued permits for an average of 118297 overnight backcountry stays per year (NPS 2017). Patterns of backcountry visitation in SEKI are highly seasonal, with peak visitation in the summer months (NPS 2015; Fig. 2). This wilderness has a quotabased permit system for overnight trips from May to September.

\section{b. Behavioral data}

\section{1) NPS PERMIT HOLDERS}

Data for NPS permit holders are derived from backcountry permits issued by the NPS. A publicly available dataset spans the time period from 1979 to 2014 and identifies, by NPS unit, the number of overnight backcountry visitors in each month of the year. These data (hereafter called "low-resolution NPS data") have the advantage of a relatively long period of record, but the temporal resolution is limited to monthly intervals. To increase temporal resolution, the NPS supplied data on all permit holders from 2007 to 2014. This dataset (termed "high-resolution NPS data") identifies party size, dates of entry and exit, and entry and exit trailheads. Personal identifying information was redacted before data were provided for this study. Nonunique rows in this dataset were dropped from the analysis, as were permits that were flagged as cancelled or rejected; these represented $3.4 \%$ of the dataset. With these adjustments, this dataset included 58404 unique permits. The highresolution NPS data are more limited in temporal extent than the low-resolution NPS data but has higher temporal and spatial resolution, allowing for identification of submonthly temporal variability. Despite the limitations of the low-resolution NPS data, its long temporal record makes it useful for comparison with and validation of results obtained from the high-resolution NPS data. For this group of users, the entire population is essentially included in the sample: all users must get permits and so are included in the sample.

\section{2) PCTA PERMIT HOLDERS}

There is no publicly available data on the number and timing of PCTA permit holders. This group obtains backcountry permits from the PCTA. While NPS permits require a specific daily itinerary, PCTA permits require the user to identify only starting and ending locations and dates, which may be several months and thousands of miles apart. Within this range, there is no requirement that hikers follow a particular itinerary nor is there an official record of their dates and locations. We address that gap by collecting data from online blogs.

A website called trailjournals.com is a popular site for hosting long-distance hiking blogs. On this site, hikers record the dates and location of their trip, along with daily diary entries. We collected data from all the PCT blogs on trailjournals.com for which the planned 
itinerary suggested that the hiker had a PCTA-issued permit, the hiker visited the study area, and the blog contained sufficient detail to identify hiker locations. Using these criteria, data on 535 individual hikers were collected. For each hiker, the date at which they visited each of the locations marked in Fig. 1 was recorded, as well as the date and time of their start and ending points, and the date at which they entered SEKI was calculated.

One consideration when collecting data through blogs is assessing the extent to which the sample represents the population. Because of the dearth of existing data on these visitors, a truly randomized sample is impossible. However, blogs are an appropriate method of estimating the population-level sensitivity of visitation timing to hydroclimate variables for several reasons. The traits and motivations that differentiate bloggers are not likely to be the same as traits that affect their sensitivity to climate variables. Common traits of bloggers are openness and neuroticism, while common motivations include helping/ informing, social connection, passing time, exhibitionism, archiving/organizing, professionalism, and getting feedback (Guadagno et al. 2008; Hollenbaugh 2011). Furthermore, blogs may compare favorably to more traditional survey methods. Blogs have a linear narrative structure and strict representation of chronology (Hookway 2008), characteristics that make them particularly appropriate for the purposes of this study. In contrast, surveys to obtain similar information would rely more heavily on respondent memory. Furthermore, methods of identifying, contacting, and obtaining responses from survey participants may introduce bias of similar or greater magnitude than blogs. Blogs have previously been used to model human aggregation and dispersion and to identify crowd behavior as well as to identify communities and influential figures (Fujisaka et al. 2010; Lee et al. 2011; Agarwal and Liu 2008).

\section{c. Hydroclimate data}

Streamflow, snowpack, and temperature data were used as indicators of hydroclimate conditions for each year. These parameters were selected because they have a strong observational record, may be relevant to wilderness users, and are expected to change under a warming climate.

Historical snow survey data from 1979 to 2014 for all sites within SEKI were obtained from the California Department of Water Resources (Natural Resources Conservation Service 1979). The mean value across sites for 1 April and 1 May SWE was calculated. These surveys have good precision and accuracy but are point data that are not integrated over space or time.

Streamflow data were used in conjunction with snow survey data as an integrated measure of hydrologic conditions over a watershed. We obtained data from USGS gauges that are in the watersheds that drain SEKI (Kings, Kern, and San Joaquin), had data for the entire period of interest (1979-2014), and were labeled as reference gauges, indicating that they are not significantly impacted by anthropogenic modifications, such as dams. These criteria yielded two gauges at Pitman and Bear Creeks. For each gauge, the total annual flow and streamflow center of mass timing (CT) were calculated. In analysis, we used the percentage of mean annual flow, where the mean was calculated over the period from 1979 to 2014. CT is a measure of when the mean parcel of water in a water year passes the gauge and is strongly influenced by air temperature because of both a precipitation phase shift from rain to snow and earlier snowmelt (Stewart et al. 2004). CT is commonly used in studies of climate change impacts on snowmeltdominated systems and provides a time-integrated perspective of flow pulses and the distribution of flow throughout the year (He et al. 2013).

To assess visitor responses to temperature, the TopoWx dataset was used. TopoWx is a gridded, 800-m temperature product that incorporates remotely sensed land skin temperature and climate station data and is designed for use in spatially explicit hydrological and ecological modeling (Oyler et al. 2015). For the bounding box containing SEKI, monthly minimum and maximum temperature were obtained for each grid cell. For each month, the mean of monthly minimum and maximum temperature was calculated for each grid cell, and a spatial mean of these was calculated. Monthly average temperature Tavg was then aggregated across seasons, combining December through February (DJF), March through May (MAM), June through August (JJA), and September through November (SON).

\section{d. Analysis of NPS permit holders}

Regression analysis was used to assess the sensitivity of NPS permit holders to hydroclimate variables. With the long-term NPS dataset, monthly fractions of annual visitation were calculated for the 36-yr period of record. These monthly fractions of visitation were used in multiple regressions with month as a dummy variable, interaction terms between each month and 1 April SWE or MAM Tavg, and January excluded from the regression as a baseline for comparison. The 1 April SWE was selected for this portion of the analysis because it is a commonly referenced metric in water resources management, and MAM Tavg was used in order to compare the effects of temperature with a hydroclimate variable. Interaction terms with the month variable identify the impact of 1 April SWE or MAM Tavg on visitation for a given month; a negative coefficient would indicate 
TABLE 2. Effects of month and 1 Apr SWE and MAM Tavg on low-resolution NPS visitation, where dependent variable is the percent of annual visitation occurring in each month. Terms with insignificant coefficients are excluded from the table. Significance estimates: * indicates $p<0.05, * *$ indicates $p<0.01$, and $* * *$ indicates $p<0.001$.

\begin{tabular}{lcc}
\hline \hline \multicolumn{1}{c}{ Predictor } & $\begin{array}{c}\text { 1 Apr SWE coefficient (\% of annual } \\
\text { visitation per m SWE) }\end{array}$ & $\begin{array}{c}\text { MAM Tavg coefficient (\% of annual } \\
\left.\text { visitation per }{ }^{\circ} \mathrm{C}\right)\end{array}$ \\
\hline May & $7.7^{* * *}$ & N/A \\
June & $19.3^{* * *}$ & $11.0^{* * *}$ \\
July & $30.1^{* * *}$ & $28.4^{* * *}$ \\
August & $28.4^{* * *}$ & $38.0^{* * *}$ \\
September & $11.0^{* * *}$ & $17.5^{* * *}$ \\
Hydroclimate variable & -0.0024 & 0.0029 \\
May* Hydroclimate variable & $\mathrm{N} / \mathrm{A}$ & $1.2^{*}$ \\
June $*$ Hydroclimate variable & $-2.8^{* *}$ & $\mathrm{~N} / \mathrm{A}$ \\
August * Hydroclimate variable & $3.19^{* * *}$ & $-1.3^{*}$ \\
\hline
\end{tabular}

increases in 1 April SWE or MAM Tavg decrease visitation in that month. The 1 May SWE was also tested as an explanatory variable; results were similar to those for 1 April SWE and are reported in the supplemental material. An alpha level of 0.05 was used to determine significance throughout the analyses.

The high-resolution NPS permit data were divided into years with earlier and later than mean CT at Bear Creek and tested for difference in medians and standard deviations using Wilcoxon rank sum and $\mathrm{F}$ tests. Linear regressions were conducted with date of permit as the dependent variable and each of the hydroclimate variables as predictors. In each case, the number of people in each party was used as a weighting term for the regression. For each year in this period, the mean date of the permit and earliest and latest $5 \%$ of permits were also calculated and regressed against each of the hydroclimate variables.

\section{e. Analysis of PCTA permit holders}

The date at which each PCTA permit holder crossed the southern SEKI border was calculated and used as the dependent variable in analyses. PCTA permit holders were analyzed in the same way as NPS permit holders, by comparing distributions in years with early and late CT and regressing dates of visitation against hydroclimate variables. As with NPS permit holders, regressions were conducted with all visitors and annual mean, earliest $5 \%$, and latest $5 \%$. Spatial densities of PCTA permit holders in early and late CT years were mapped at multiple points in time (1 June and 1 July), using a uniform kernel with a bandwidth of $80 \mathrm{~km}$.

\section{Results}

a. NPS permit holders

\section{1) LOW-RESOLUTION NPS DATA}

Multiple regressions with low-resolution NPS data and 1 April SWE as a hydroclimate indicator revealed that visitation in the months of May, June, July, August, and September was significantly greater than January visitation; coefficients for these months indicate the strength of the relationship (Table 2). Interaction terms with 1 April SWE suggested that 1 April SWE had a negative effect on the fraction of annual visitation that occurs in June and a positive effect on the fraction of annual visitation that occurs in August and September. These results suggest that in years with low snowpack, visitation is distributed earlier in the year. Models with different hydroclimatic predictor variables (CT at Bear and Pitman, flow at Bear and Pitman, and 1 May SWE) yielded results that showed the same direction of effects as the model with 1 April SWE. When MAM Tavg was used as a climatic predictor instead of 1 April SWE, coefficients suggested that warmer MAM Tavg was associated with increased visitation in May and decreased visitation in August.

\section{2) High-RESOLUTION NPS DATA}

Analysis of high-resolution NPS data also showed sensitivity to hydroclimate variables and temperature with effect directions that matched those of the lowresolution NPS data and allowed for analysis methods that more precisely represent how interannual variability of visitation responds to interannual variability of hydroclimate and temperature. The mean date of visitation for NPS permit holders was day 211 (July 29) \pm 43.7 days. In years with later than average CT at Bear Creek, the median date of visitation was significantly later than in years with earlier than average CT, with approximately a 9-day difference ( $p<0.001$; Fig. 3). Standard deviations of these two groups were also significantly different, with 5 days greater standard deviation in the group with early CT $(p<0.001)$.

Regressions of individual permit dates onto each hydroclimate variable and seasonal temperature showed that NPS permit holder visitation was sensitive to all hydroclimate variables tested and temperature in 


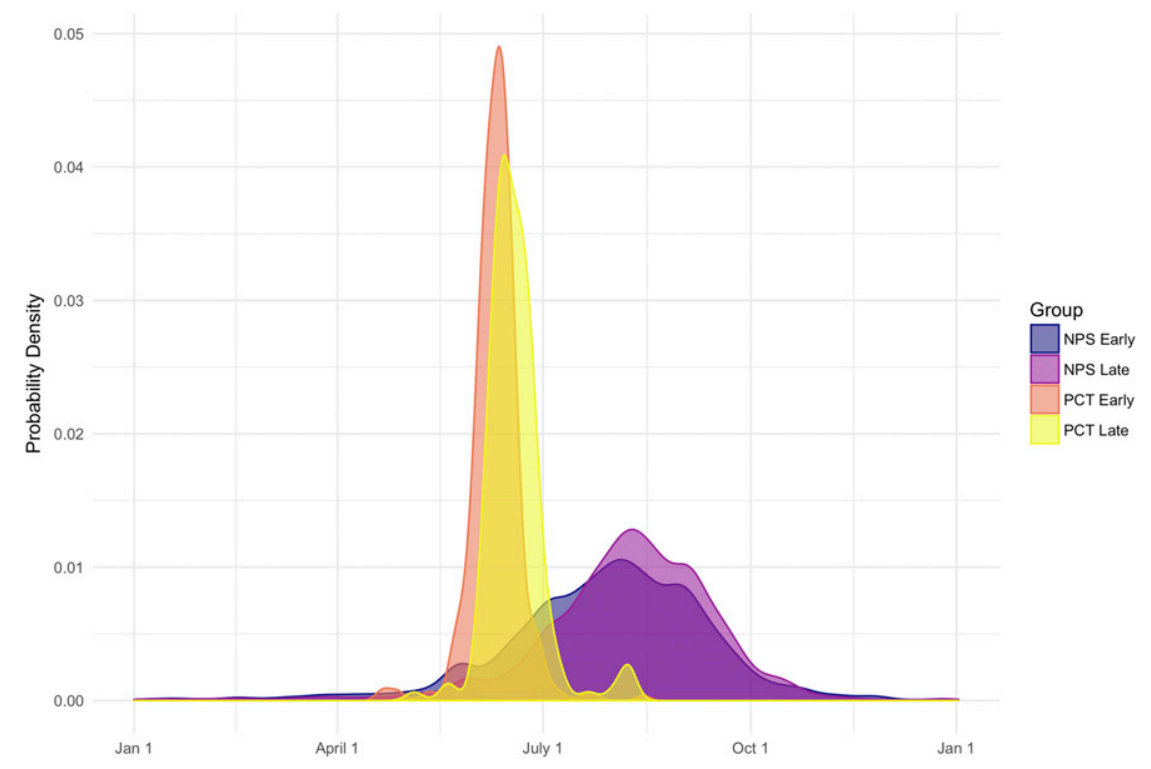

FIG. 3. Distribution of visitation of NPS and PCTA permit holders in years with earlier and later than mean CT.

all seasons (Fig. 4). Responses to CT at Bear and Pitman Creeks had coefficients of 0.23 and 0.20 , suggesting that for a 1-day advance in $\mathrm{CT}$, visitation advanced by $0.20-0.23$ days, though this relationship explained less than $1 \%$ of the total variance in visitation. Lower April and May SWE were also associated with earlier visitation; for every meter of decrease in 1 April SWE, visitation advanced by 4.4 days, while for every meter of decrease in 1 May SWE, visitation advanced by 5.0 days. Increases in total annual flow had a small but significant effect, where a $10 \%$ increase in annual $Q$ relative to the long-term mean was associated with a $0.6-1$-day delay in

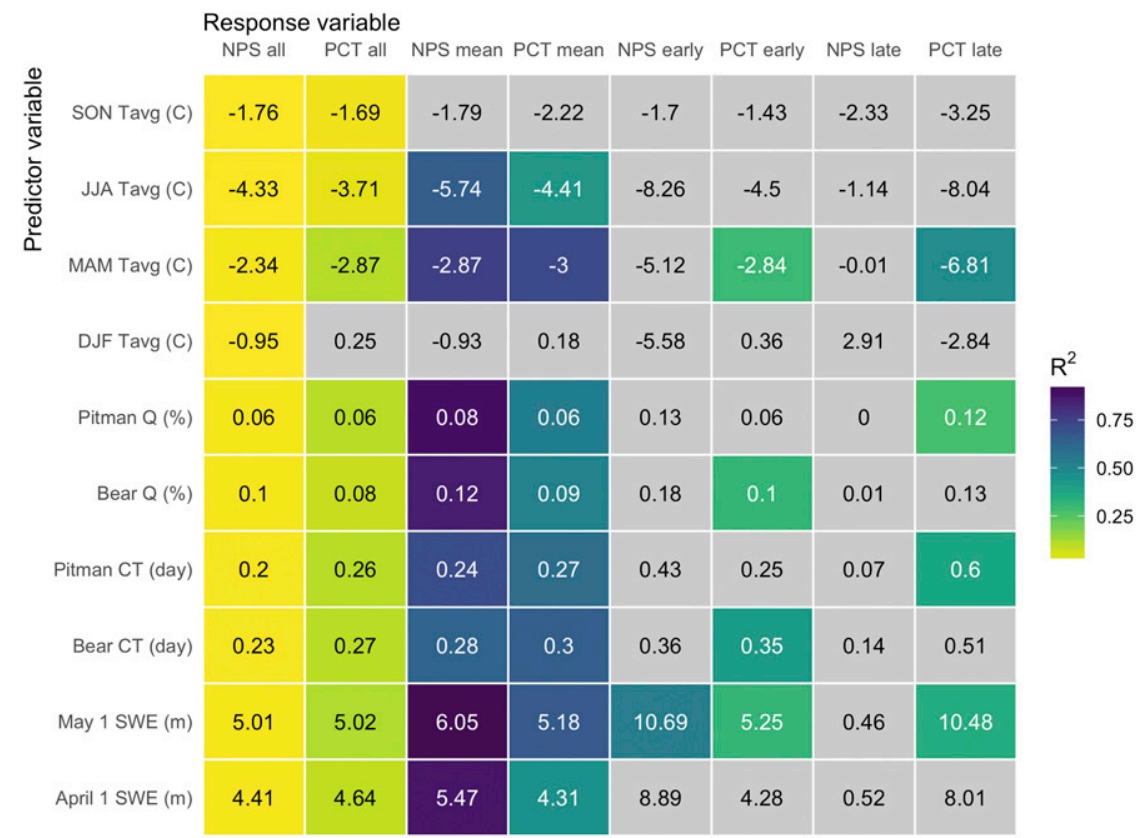

FIG. 4. Heat map of regression results for each response and predictor variable. Colored tiles are regressions with $p<0.05$, and color scale represents $R^{2}$. Numbers in each tile represent regression coefficient estimates in units of days of visitation per unit indicated on the $y$ axis. 


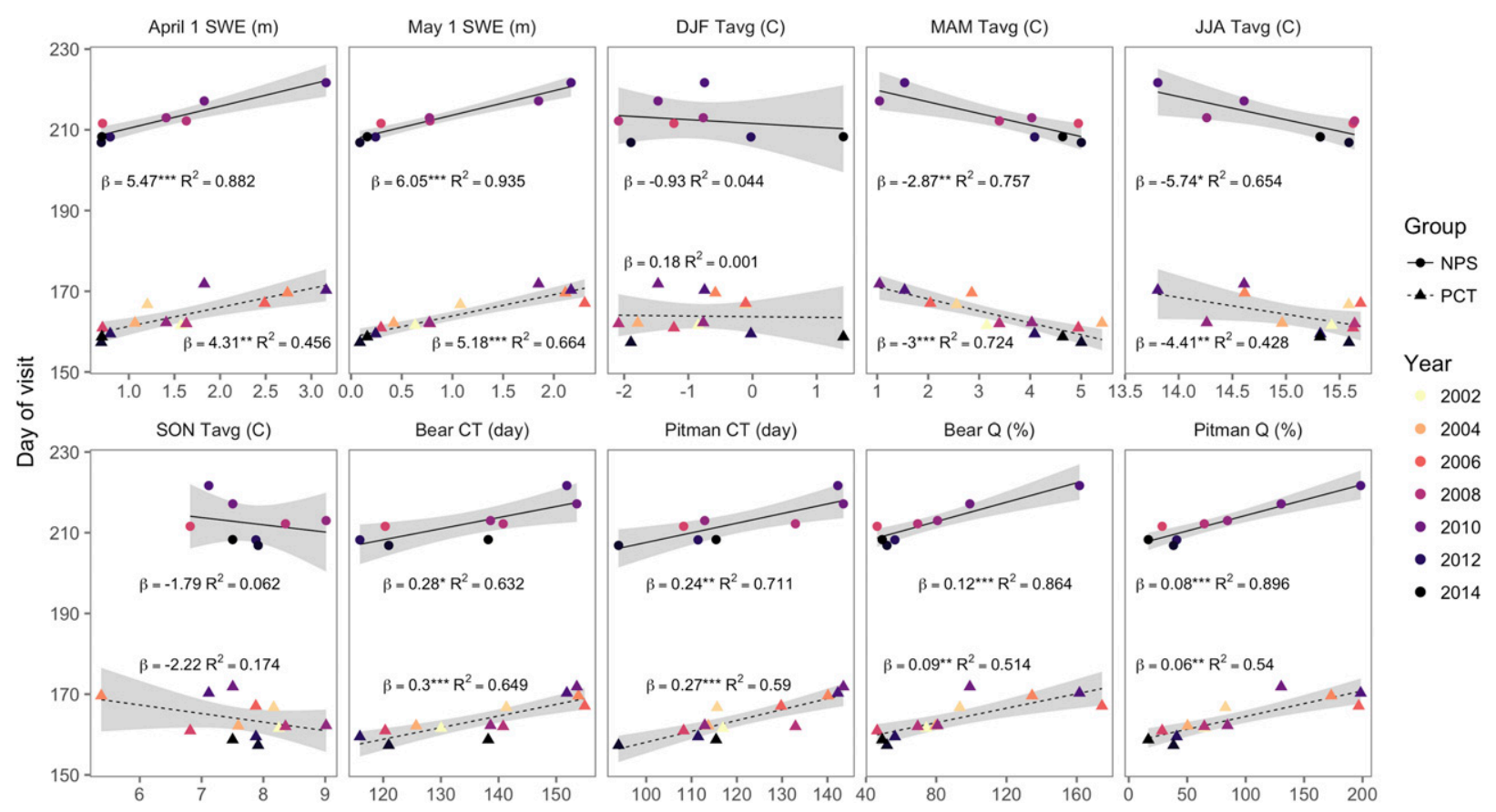

FIG. 5. Regressions of mean PCTA and NPS visitation against each hydroclimate variable. Significance codes: $*$ indicates $p<0.05$, $* *$ indicates $p<0.01$, and $* * *$ indicates $p<0.001$.

visitation. Warmer temperatures were associated with earlier visitation in all seasons, though the effect size was much stronger for spring (MAM) and summer (JJA) temperatures than for fall (SON) and winter (DJF) temperatures.

In regressions with mean, earliest 5\%, and latest 5\% of visitation as dependent variables, the mean date of visitation was sensitive to all of the hydroclimate variables and to MAM and JJA Tavg. Hydroclimate and MAM and JJA Tavg explained $63 \%-94 \%$ of interannual variability in mean visitation dates (Fig. 5). The earliest $5 \%$ of visitors also arrived earlier in years with lower May SWE, with May SWE having almost twice as strong an effect on the earliest $5 \%$ as on the mean. However, this earliest group of visitors was not sensitive to any of the other variables tested. The latest $5 \%$ of visitation did not respond in a statistically significant way to any individual variable.

\section{b. PCTA permit holders}

The mean day of the year at which PCTA permit holders crossed the southern SEKI border was 163 (June 13) \pm 12.5 . The mean time between crossing northern and southern SEKI borders was 7.4 days. The mean date of visitation in years with early CT was 8.3 days earlier than in years with late CT, with a greater standard deviation in days with late CT (12.6 days) than early (10.8 days). The probability density function for PCTA permit holders in years with later than mean CT shows that a second increase in visitation later in the season than the main group is likely the reason for the larger standard deviation in the later group. This is in contrast to NPS permit holders, which had greater standard deviation in years with early CT. Maps of the distribution of visitation in years with earlier and later than mean CT reveal the spatial distribution of visitors on selected dates (Fig. 6). On the dates represented, visitors are distributed farther north in years with earlier CT.

The timing of PCTA permit holders was sensitive to all the hydroclimate variables tested and to JJA, MAM, and SON temperatures (Fig. 4). Effect sizes suggested that visitors arrive $0.26-0.27$ days earlier per day advance in CT, $0.6-0.8$ days earlier for each $10 \%$ decrease in annual flow, and 4.6-5.0 days earlier for each meter decrease in April or May SWE. A $1^{\circ} \mathrm{C}$ increase in MAM Tavg was associated with a 3.7-day advance in visitation timing, while the same increase in JJA Tavg was associated with a 2.9-day increase in visitation timing. The $R^{2}$ values for these regressions were 0.08-0.1, suggesting that $8 \%-10 \%$ of total variability in timing of PCTA permit holders was described by interannual climate variability. While these $R^{2}$ values were small, they were an order of magnitude greater than comparable $R^{2}$ values for NPS permit holders.

Regressions of annual-mean PCTA permit holder date against hydroclimate variables and temperature 


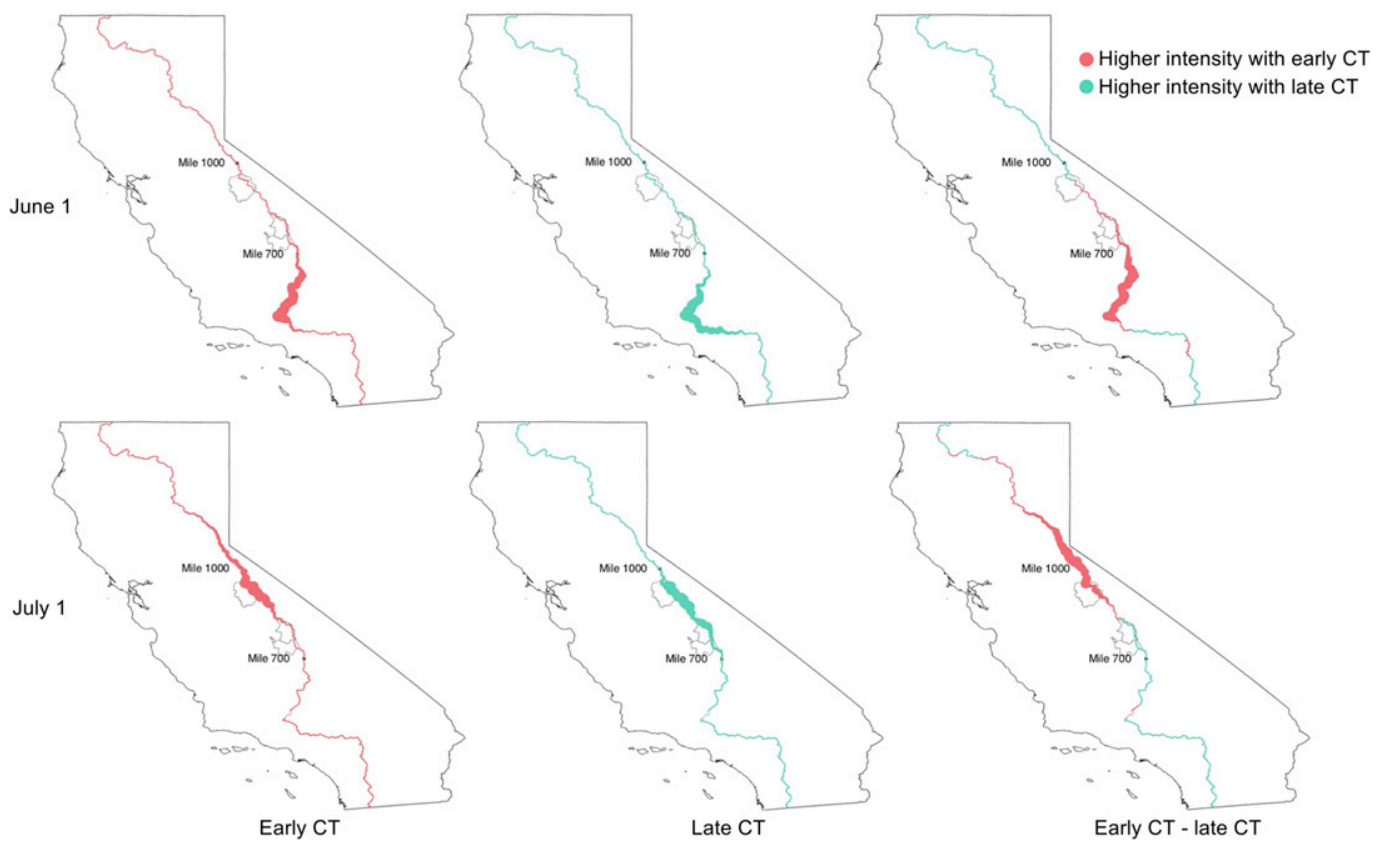

FIG. 6. Distribution of PCTA permit holders on 1 Jun and 1 Jul, with line thickness proportional to number of visitors at points along the trail. (left) Visitors in years with early CT, (center) visitors in years with late CT, and (right) a subtraction of the two to highlight areas of difference.

suggested that hydroclimate and JJA and MAM temperatures explained $41 \%-67 \%$ of interannual variability (Fig. 4). Effect sizes were similar when mean visitation was used as the dependent variable to effect sizes when all permit dates were used as the dependent variable. The earliest $5 \%$ of PCTA permit holders were sensitive only to MAM Tavg, Bear Creek $Q$ and CT, and 1 May SWE. The estimated magnitude of effect of these variables on the earliest $5 \%$ of visitors was similar to their effects on mean visitation, though $R^{2}$ was lower for early than mean visitation, suggesting that hydroclimate explained less of the variance in the earliest visitors' behavior. Unlike the latest NPS permit holders, the latest $5 \%$ of PCTA permit holders were sensitive to many of the hydroclimate and temperature variables; these were MAM Tavg, Pitman $Q$ and CT, and 1 May SWE. The magnitude of the effect on the latest $5 \%$ of PCTA permit holders was about twice as great as the magnitude of the effect on mean PCTA permit holders. Effect sizes suggested that for every $1^{\circ} \mathrm{C}$ increase in MAM Tavg, the latest PCTA permit holders arrived 6.8 days earlier. For every 1-day advance of CT in Pitman Creek, this latest group of visitors arrived 0.6 days earlier.

\section{Discussion}

PCTA permit holders and NPS permit holders generally had similar sensitivity to hydroclimate and temperature, despite having quite different mean and variance of their visitation timing. This similarity has several implications: First, it lends support to the validity of using blogs as a method of collecting information about the behavior of wilderness users. Second, it suggests that two groups that differ in their mechanisms of obtaining permits, duration and length of their trips, and the timing and within-group variability of their timing have similar responses to changes in hydroclimate and temperature. Future work could test whether other groups in different locations have also exhibited similar sensitivities to these variables.

Despite the overall similarities, there were a few notable differences in the PCTA and NPS permit holder sensitivity to hydroclimate and temperature. While mean NPS and PCTA visitation were similarly sensitive to hydroclimate, more of the intra-annual variance of PCTA permit holders was explained by hydroclimate variables than that of NPS permit holders. This may be explained by the more narrow distribution of PCTA permit holders. Furthermore, the earliest $5 \%$ of NPS permit holders were relatively insensitive to climatic variation, while the earliest PCTA permit holders were sensitive. The sensitivity of the earliest group of PCTA permit holders suggests that the onset of visitation by this group is determined by hydroclimate and/or temperature. While this group of visitors is relatively small, they arrive earlier than the vast majority of NPS permit 
holders and may represent human presence in wilderness regions earlier than there would otherwise be. This may be in part because the PCT traverses relatively high-elevation regions of these protected areas, while NPS permit holders may choose to recreate in lowerelevation regions of SEKI if late snow persists at higher elevations. This could have ecological effects caused by altered human-wildlife interactions, and it could very easily affect the need for emergency or nonemergency services at this time of year.

The latest $5 \%$ of NPS permit holders were insensitive to the hydroclimate and temperature variables tested, but the latest $5 \%$ of PCTA permit holders were 2 to 3 times as sensitive as the mean date of visitation. It is to be expected that the latest visitors would be insensitive to measures of spring hydroclimate and winter, spring, and summer temperature. A possible explanation for the increased effect size for latest PCTA permit holders is qualitatively evidenced in the blogs, where many visitors in years with high SWE and late CT wrote that they left SEKI to visit lower-elevation areas before returning later in the year. In this way, the magnitude of the effect of SWE or CT is multiplied.

While wilderness visitors are sensitive to streamflow, there is not a one-to-one relationship between CT and visitation timing. This partial sensitivity suggests that wilderness users interact with ecosystems in different conditions in years with different climatic drivers. In years with later CT, more SWE, and more annual flow, visitors are more likely to visit later and may still interact with higher streamflow and snowpack. In years with earlier CT, less SWE, and potentially lower discharge, which are more representative of future climate, visitors are likely to arrive earlier and to interact with lower streamflow and snowpack. For wilderness users, these changes may lead to wilderness conditions with safer or easier travel.

The high correlations between temperature and the hydroclimatic variables assessed here make it impossible to statistically determine whether temperature or the hydroclimatic effects of temperature are proximate causes of changes in visitation. Based on these data, it is possible that spring and summer temperatures directly affect visitation timing or that spring temperatures affect hydroclimate, which in turn affects visitation timing. Spring and summer temperatures were also moderately correlated, with a correlation coefficient of 0.44; the mechanistic importance of temperature in different seasons is therefore also difficult to completely disentangle. Previous studies of the effects of climate on visitation to protected areas have primarily used temperature and precipitation as predictor variables. It is well established that visitation magnitude is sensitive to temperature and likely to increase with warming in mountainous areas, with nonlinear effects and temperature thresholds above which visitation decreases (e.g., Scott et al. 2007, 2008; Hewer et al. 2016). Moreover, visitation timing is also temperature sensitive, with earlier visitation associated with warmer spring temperatures in many regions (Buckley and Foushee 2012). Visitor surveys using stated and revealed preference methods suggest that the direct effects of climate change, such as temperature and precipitation, affect visitation (Richardson and Loomis 2004). While the effects of warming on visitation are well established, there is a very plausible mechanism for the effects of hydroclimate on visitation timing, particularly for backcountry travel; snow is difficult and sometimes dangerous to travel over on foot, and rivers with high flow that lasts into the spring and summer are difficult and dangerous to ford. Several previous studies in other locations and of other groups have used survey-based approaches to determine the causes of visitor behavior (e.g., Hewer et al. 2015, 2017). Further work to determine the extent to which temperature or associated hydroclimate variables are a proximate cause of visitation timing, as well as mechanisms of information transfer, could include surveys or a textual analysis of the blog-based data identified here.

The causal relationship between specific hydroclimate variables and visitation response, as well as mechanisms of information transfer, likely influences the overall magnitude of change. While predicting visitor behavior based on linear regression models would be subject to significant uncertainty, a comparison between the slopes of the models and projected changes in hydroclimate variables is instructive for better understanding variability in possible effect sizes. For example, CT is projected to advance by $1-6$ weeks in the southern Sierra Nevada, which would be associated with a 1.4-12.6-day advance in mean visitation for mean PCTA and NPS permit holders, and twice that for the latest PCTA permit holders if the linear relationships identified here continue (Maurer 2007; Young et al. 2009; He et al. 2013). In contrast, the direction of the effect of climate change on total annual flow in this region is uncertain (Ficklin et al. 2012; He et al. 2013), suggesting that visitation timing could increase or decrease if total streamflow is an important causal factor. Yearly temperatures are projected to rise between $2.1^{\circ}$ and $3.2^{\circ} \mathrm{C}$ by the 2060s in a high emissions scenario, with higher projected changes in JJA temperatures than MAM (Pierce et al. 2013), which would result in a 4.8-18.4-day advance in visitation if the linear relationships identified here were to persist. The variability in projections depending on which variable(s) cause shifts in visitation timing suggests the importance of further work to elucidate causal mechanisms. 
One factor that constrains prediction based on the linear relationships identified here is wilderness management, which may need to respond to changing timing of visitation. Previous discussions of the management of national parks under climate change have suggested that changing tourist behavior may exacerbate the effects of climate on parks but that warmer and drier conditions may provide benefits to visitors and communities (Carter et al. 2014). One analysis suggested the possibility of limiting visitor access to fire-prone areas during fire season; the shifting timing of fire season and of visitor access, as identified here, would interact to determine appropriate management decisions (Baron et al. 2009). As visitation timing responds to climate, it may be appropriate to adjust the timing of restoration activities, seasonal staffing, or the dates at which trailhead quotas go into effect based on climate. Our results suggest that visitation timing is influenced by hydroclimate, but hydroclimate interacts with management decisions to ultimately determine visitation. For example, new restrictions on PCTA permits implemented after data were collected for this study restrict trail use to 50 individuals starting at the California-Mexico border per day; this and other visitation restrictions may alter the relationships between hydroclimate and visitation timing. To the extent that management activities can be altered based on interannual climate variability, annual adjustments may be appropriate. To the extent that these activities cannot be varied on an interannual basis, it may be appropriate to consider long-term changes in timing to plan for altered climate. Future research could also test the extent to which spatial patterns of visitation behavior change in response to hydroclimate; spatial alterations within and between protected areas could also affect the need for management responses.

Finally, the phenological partial mismatch between visitors and hydroclimate may affect ecosystems. As species respond to climate change, changing interactions between organisms may be more significant than the direct effects of climate (Parmesan 2006). Animals and plants likely have different phenological sensitivities than wilderness users, and may interact with wilderness users in a different phenological stage than they did historically. Humans affect wildlife through exploitation, disturbance, habitat modification, and pollution, and nonmotorized winter travel may be particularly significant (Knight and Gutzwiller 1995; Larson et al. 2016). Disturbance is the most likely of these effects in the SEKI context, and the phenological stage of wildlife when they experience this disturbance may exacerbate or mediate its impact. The greater standard deviation of NPS permit holders in years with early CT also suggests that there may be a longer period of human visitation, which would result in a longer period of time during which humans and wildlife interact regularly.

The quantitative relationships identified in this study cannot be extended beyond the environment in which they were derived. However, other mountainous wilderness areas with significant volumes of visitation may also experience relationships between hydroclimatic conditions and the timing of visitation. PCTA permit holders are localized to this particular trail, but there are long-distance trails across much of the western United States that may have similar dynamics. To our knowledge, behavior of these users is not well documented on any of these trails; the blog approach used here may provide a useful way to study visitor behavior on other long-distance trails and in other contexts as well.

\section{Conclusions}

This study provides strong evidence that overnight wilderness visitation in SEKI is affected by hydroclimate variables and uses novel data collection methods to quantify the behavior of wilderness visitors. Both NPS permit holders and PCTA permit holders showed similar sensitivity to hydroclimate. Each group showed partial sensitivity to hydroclimate, suggesting that as temperatures warm, wilderness users may visit earlier but may also interact with ecosystems in different phenological conditions than they did historically. It may be appropriate for managers of these areas to consider both of these impacts when planning adaptations to climate change.

Acknowledgments. The authors have no conflicts of interest. We gratefully acknowledge the National Park Service for providing data. A. Marshall was supported by the University of California Berkeley through the Energy and Resources Group Charles K. (Ned) Birdsall Endowed Graduate Research Support Fund (49864 W6736). (Scripts and data are archived at the Open Science Framework at https://osf.io/rn5su/.) All data analysis was conducted using $\mathrm{R}$, including the suite of tidyverse packages, and MATLAB 2015b (R Core Team 2016; Mathworks 2015; Wickham 2016).

\section{REFERENCES}

Agarwal, N., and H. Liu, 2008: Blogosphere: Research issues, tools, and applications. ACM SIGKDD Explorations Newsletter, Vol. 10, Association for Computing Machinery, New York, NY, 18-31, https://doi.org/10.1145/1412734.1412737.

Albano, C. M., C. L. Angelo, R. L. Strauch, and L. L. Thurman, 2013: Potential effects of warming climate on visitor use in three Alaskan national parks. Park Sci., 30, 37-44, http:/www. nature.nps.gov/ParkScience/archive/PDF/Article_PDFs/ParkScience30(1) Summer2013_36-44_Albano_et_al_3650.pdf. 
Barnett, T. P., and Coauthors, 2008: Human-induced changes in the hydrology of the western United States. Science, 319, 1080-1083, https://doi.org/10.1126/science.1152538

Baron, J. S., L. Gunderson, C. D. Allen, E. Fleishman, D. McKenzie, L. A. Meyerson, J. Oropeza, and N. Stephenson, 2009: Options for national parks and reserves for adapting to climate change. Environ. Manage., 44, 1033, https://doi.org/10.1007/s00267-009-9296-6.

Buckley, L. B., and M. S. Foushee, 2012: Footprints of climate change in US national park visitation. Int. J. Biometeor., 56, 1173-1177, https://doi.org/10.1007/s00484-011-0508-4.

Carter, R. W., S. J. Walsh, C. Jacobson, and M. Miller, 2014: Global change and human impact challenges in managing iconic national parks. George Wright Forum, 31, 245-255, http://www. georgewright.org/313carter.pdf.

Ficklin, D. L., I. T. Stewart, and E. P. Maurer, 2012: Projections of 21st century Sierra Nevada local hydrologic flow components using an ensemble of general circulation models. J. Amer. Water Resour. Assoc., 48, 1104-1125, https://doi.org/10.1111/j.1752-1688.2012.00675.x.

Fisichelli, N. A., G. W. Schuurman, W. B. Monahan, and P. S. Ziesler, 2015: Protected area tourism in a changing climate: Will visitation at US national parks warm up or overheat? PLoS One, 10, e0128226, https://doi.org/10.1371/journal.pone.0128226.

Fujisaka, T., R. Lee, and K. Sumiya, 2010: Discovery of user behavior patterns from geo-tagged micro-blogs. Proc. Fourth Int. Conf. on Uniquitous Information Management and Communication, Suwon, South Korea, Association for Computing Machinery, 36, https://doi.org/10.1145/2108616.2108660.

Guadagno, R. E., B. M. Okdie, and C. A. Eno, 2008: Who blogs? Personality predictors of blogging. Comput. Hum. Behav., 24 , 1993-2004, https://doi.org/10.1016/j.chb.2007.09.001.

Hayhoe, K., and Coauthors, 2004: Emissions pathways, climate change, and impacts on California. Proc. Natl. Acad. Sci. USA, 101, 12 422-12 427, https://doi.org/10.1073/pnas.0404500101.

He, Z., Z. Wang, C. J. Suen, and X. Ma, 2013: Hydrologic sensitivity of the upper San Joaquin River watershed in California to climate change scenarios. Hydrol. Res., 44, 723-736, https:// doi.org/10.2166/nh.2012.441.

Hewer, M. J., D. Scott, and W. A. Gough, 2015: Tourism climatology for camping: A case study of two Ontario parks (Canada). Theor. Appl. Climatol., 121, 401-411, https://doi.org/ 10.1007/s00704-014-1228-6.

- _ _ , and A. Fenech, 2016: Seasonal weather sensitivity, temperature thresholds, and climate change impacts for park visitation. Tourism Geogr., 18, 297-321, https://doi.org/ 10.1080/14616688.2016.1172662.

— $—$, and W. A. Gough, 2017: Differences in the importance of weather and weather-based decisions among campers in Ontario parks (Canada). Int. J. Biometeor., 61, 1805-1818, https://doi.org/10.1007/s00484-017-1364-7.

Hollenbaugh, E. E., 2011: Motives for maintaining personal journal blogs. Cyberpsychol. Behav. Soc. Networking, 14, 13-20, https://doi.org/10.1089/cyber.2009.0403.

Hookway, N., 2008: 'Entering the blogosphere': Some strategies for using blogs in social research. Qual. Res., 8, 91-113, https://doi. org/10.1177/1468794107085298.

IPCC, 2013: Climate Change 2013: The Physical Science Basis. Cambridge University Press, 1535 pp., https://doi.org/10.1017/ CBO9781107415324.

Jones, B., and D. Scott, 2006a: Climate change, seasonality and visitation to Canada's national parks. J. Park Recreation Adm., 24, 42-62.
_ and - 2006b: Implications of climate change for visitation to Ontario's provincial parks. Leisure/Loisir, 30, 233-261, https://doi.org/10.1080/14927713.2006.9651350.

Kahle, D., and H. Wickham, 2013: ggmap: Spatial visualization with ggplot2. $R J ., 5,144-161$, http://journal.r-project.org/ archive/2013-1/kahle-wickham.pdf.

Klos, P. Z., T. E. Link, and J. T. Abatzoglou, 2014: Extent of the rain-snow transition zone in the western U.S. under historic and projected climate. Geophys. Res. Lett., 41, 2014GL060500, https://doi.org/10.1002/2014GL060500.

Knight, R. L., and K. J. Gutzwiller, 1995: Wildlife and Recreationists: Coexistence through Management and Research. 1st ed. Island Press, 372 pp.

Larson, C. L., S. E. Reed, A. M. Merenlender, and K. R. Crooks, 2016: Effects of recreation on animals revealed as widespread through a global systematic review. PLoS One, 11, e0167259, https://doi.org/10.1371/journal.pone.0167259.

Lee, R., S. Wakamiya, and K. Sumiya, 2011: Discovery of unusual regional social activities using geo-tagged microblogs. World Wide Web, 14, 321-349, https://doi.org/ 10.1007/s11280-011-0120-x.

Leung, Y., and J. Marion, 1999: Recreation impacts and management in wilderness: A state-of-knowledge review. Wilderness Science in a Time of Change Conf.: Wilderness Ecosystems, Threats, and Management, Vol. 5, RMRS-P-15-VOL-5, Ogden, UT, U.S. Department of Agriculture, U.S. Forest Service, Rocky Mountain Research Station, 23-48, http:/www.wilderness. net/library/documents/science1999/Volume5/Leung_5-4.pdf.

Machlis, G. E., 1989: Managing parks as human ecosystems. Public Places and Spaces, I. Altman and E. H. Zube, Eds., Human Behavior and Environment Series, Vol. 10, Springer, 255-275, https://doi.org/10.1007/978-1-4684-5601-1_11.

Mathworks, 2015: MATLAB statistics and machine learning toolbox. Mathworks.

Maurer, E. P., 2007: Uncertainty in hydrologic impacts of climate change in the Sierra Nevada, California, under two emissions scenarios. Climatic Change, 82, 309-325, https://doi.org/ 10.1007/s10584-006-9180-9.

Mote, P. W., 2006: Climate-driven variability and trends in mountain snowpack in western North America. J. Climate, 19, 6209-6220, https://doi.org/10.1175/JCLI3971.1.

Natural Resources Conservation Service, 1979: Snow Survey Data. Natural Resources Conservation, accessed 19 April 2016, https:/wcc.sc.egov.usda.gov/nwcc/rorpt?report=snowmonth\&state $=$ CA.

NPS, 2015: Wilderness stewardship plan/final environmental impact statement: Sequoia and Kings Canyon National Parks. National Park Service Rep., 651 pp., https://parkplanning.nps.gov/document. $\mathrm{cfm}$ ?parkID $=342$ \& projectID $=33225 \&$ documentID $=65018$.

_ 2017: National Park Service visitor use statistics. National Park Service, https://irma.nps.gov/Stats/Reports/Park/SEQU.

Oyler, J. W., A. Ballantyne, K. Jencso, M. Sweet, and S. W. Running, 2015: Creating a topoclimatic daily air temperature dataset for the conterminous United States using homogenized station data and remotely sensed land skin temperature. Int. J. Climatol., 35, 2258-2279, https://doi.org/10.1002/joc.4127.

Parmesan, C., 2006: Ecological and evolutionary responses to recent climate change. Annu. Rev. Ecol. Evol. Syst., 37, 637-669, https://doi.org/10.1146/annurev.ecolsys.37.091305.110100.

Pierce, D. W., and Coauthors, 2013: Probabilistic estimates of future changes in California temperature and precipitation using statistical and dynamical downscaling. Climate Dyn., 40, 839856, https://doi.org/10.1007/s00382-012-1337-9. 
R Core Team, 2016: R: A language and environment for statistical computing. R Foundation for Statistical Computing, https:// www.R-project.org/.

Richardson, R. B., and J. B. Loomis, 2004: Adaptive recreation planning and climate change: A contingent visitation approach. Ecol. Econ., 50, 83-99, https://doi.org/10.1016/ j.ecolecon.2004.02.010.

Scott, D., G. McBoyle, and M. Schwartzentruber, 2004: Climate change and the distribution of climatic resources for tourism in North America. Climate Res., 27, 105-117, https://doi.org/ $10.3354 / \mathrm{cr} 027105$.

_ B. Jones, and J. Konopek, 2007: Implications of climate and environmental change for nature-based tourism in the Canadian Rocky Mountains: A case study of Waterton Lakes National Park. Tourism Manage., 28, 570-579, https://doi.org/ 10.1016/j.tourman.2006.04.020.

,$- \ldots$, and — 2008: Exploring potential visitor response to climate-induced environmental changes in Canada's Rocky Mountain national parks. Tourism Rev. Int., 12, 43-56, https:// doi.org/10.3727/154427208785899939.
Stewart, I. T., D. R. Cayan, and M. D. Dettinger, 2004: Changes in snowmelt runoff timing in western North America under a 'business as usual' climate change scenario. Climatic Change, $\mathbf{6 2}$, 217-232, https://doi.org/10.1023/B:CLIM.0000013702.22656.e8.

van Wagtendonk, J. W., and D. J. Parsons, 1996: Wilderness research and management in the Sierra Nevada national parks. Science and Ecosystem Management in the National Parks, W. L. Halvorson and G. E. Davis, Eds., University of Arizona Press, 281-294.

Vicuna, S., E. P. Maurer, B. Joyce, J. A. Dracup, and D. Purkey, 2007: The sensitivity of California water resources to climate change scenarios. J. Amer. Water Resour. Assoc., 43, 482-498, https://doi.org/10.1111/j.1752-1688.2007.00038.x.

Wickham, H., 2016: tidyverse: Easily install and load 'Tidyverse' packages. $\mathrm{R}$ package version 1.0.0, https://CRAN.R-project. org $/$ package $=$ tidyverse .

Young, C. A., and Coauthors, 2009: Modeling the hydrology of climate change in California's Sierra Nevada for subwatershed scale adaptation. J. Amer. Water Resour. Assoc., 45, 14091423, https://doi.org/10.1111/j.1752-1688.2009.00375.x. 